\title{
On the Co-Variability between Climate Indices and the Potential Spread of Seasonal Climate Simulations over South African Provinces
}

\author{
Kamoru A. Lawal ${ }^{*}{ }^{\circledR}$, Dáithí A. Stone ${ }^{2}$ \\ ${ }^{1}$ African Climate \& Development Initiative, University of Cape Town, Cape Town, South Africa \\ ${ }^{2}$ Computational Chemistry, Materials and Climate Group, Lawrence Berkeley National Laboratory, Berkeley, CA, USA \\ Email: *lawal@csag.uct.ac.za
}

How to cite this paper: Lawal, K.A. and Stone, D.A. (2019) On the Co-Variability between Climate Indices and the Potential Spread of Seasonal Climate Simulations over South African Provinces. Atmospheric and Climate Sciences, 9, 381-397. https://doi.org/10.4236/acs.2019.93027

Received: May 4, 2019

Accepted: July 14, 2019

Published: July 17, 2019

Copyright ( $\odot 2019$ by author(s) and Scientific Research Publishing Inc. This work is licensed under the Creative Commons Attribution International License (CC BY 4.0).

http://creativecommons.org/licenses/by/4.0/

\section{(c) (i) Open Access}

\begin{abstract}
This study investigates the co-variability between measures of the spreads in the ensembles of seasonal climate simulations and large scale climate indices. Spreads in the ensembles of seasonal simulations (of rainfall and near surface air temperature) from an atmospheric model, over South African provinces, are quantified with the de-trended anomalies of standard deviation (StdDev) and the distance between the 90th and 10th percentiles (RoP) of the simulations. Results indicate that, on seasonal time scales, measures of spread significantly co-vary with observed global sea surface temperatures (SST) far and near. This suggests that the climate factors controlling the degree to which the seasonal climate may be precisely forecast over the South African provinces may both be locally and remotely based. Results also indicate that all significant predictors of spread-El Niño-Southern Oscillation (ENSO), Indian Ocean Dipole (IOD), Benguela Niño (BGN) and Southwest Indian Ocean Index (SWI), are of tropical origin; they co-vary significantly with measures of spread on seasonal time scales over a number of provinces and seasons, particularly during the rainfall onset and peak periods, as well as during the cold season. Nevertheless, responses of measures of spread to climate predictors are relatively small, either indicating that predictor-spread relationships are more complex in nature than can be represented by the traditionally simple climate indices, or indicating that controls on ensemble spread are weak. Therefore, there may be limits to the extent to which year-to-year variations in the predictability of seasonal climate over South Africa provinces might be understood.
\end{abstract}

\section{Keywords}

Climate Indices, Correlation Coefficient, Ensemble Spread, Seasonal Climate, South Africa 


\section{Introduction}

An emerging question of whether the possible spread of seasonal climate simulations over South African provinces varies on inter-annual basis was addressed by [1]. In an atmospheric modelling study that used the observed sea surface temperatures (SST) and radiative forcing variations over the past half century, [1] found that the inter-annual variability and long-term trends in the ensemble spreads of seasonal rainfall and near surface temperature over the South African provinces were larger than expected based on sampling error alone. Moreover, model skill was found to be higher during situations when the simulation spreads were narrower, suggesting that the reality of long-term trends in the spreads of the climate model ensemble reflect primary trends in the seasonal climate system that recent seasonal forecasting systems might also be expected to reproduce.

This paper follows by investigating whether the trends in the spread of seasonal climate simulations over South Africa arise from physical responses that are themselves potentially predictable. These physical responses are regarded as drivers and mechanisms that may be remotely forced or locally based. These driving factors may include year-to-year variations in SST anomalies or large-scale patterns of co-variation in the atmosphere or coupled atmosphere-ocean system. This study aims to further advance the understanding of predictability of South African seasonal climate by examining the co-variability between SSTs, large-scale climate indices and the spread in the ensemble of seasonal climate simulations from an atmospheric model.

Several studies have carried out investigations on the relationship between the SSTs and the chaotic seasonal atmospheric states of South Africa (e.g. [2] [3] [4]). They found strong relationships between SSTs and the ensemble mean in an ensemble forecast system. Studies have also found that spreads in the ensembles of climate models can be utilized to assess the reliability and skill of climate forecasts and or simulations ([5] [6] [7] [8]). Hence, the year-to-year variations in the ensemble spreads reflect variations in the predictability of seasonal climate forecasts [1]. In view of these, this study seeks to answer the question-do variations in SST anomalies co-vary with measures of seasonal climate predictability (i.e. the ensemble spread of the simulations). If so, what is the nature of the significant climate predictors for South African seasonal climate? Provisional answers to these may assist forecasters and modelers evaluate the uncertainty in specific seasonal forecasts.

The domain of study is the Republic of South Africa-a moderately dry country with inconsistent rainfall systems ([9] [10]; Figure 1). We focus on the provinces because administrative decisions on water resource and agricultural management are made at the provincial level, and the provincial borders often align with sharp gradients in climatology [1]. Abbreviations used in this study for the South African provinces are explained in Table 1. Analyses of the seasons that is generally most relevant for climatic impacts will be discussed. For 


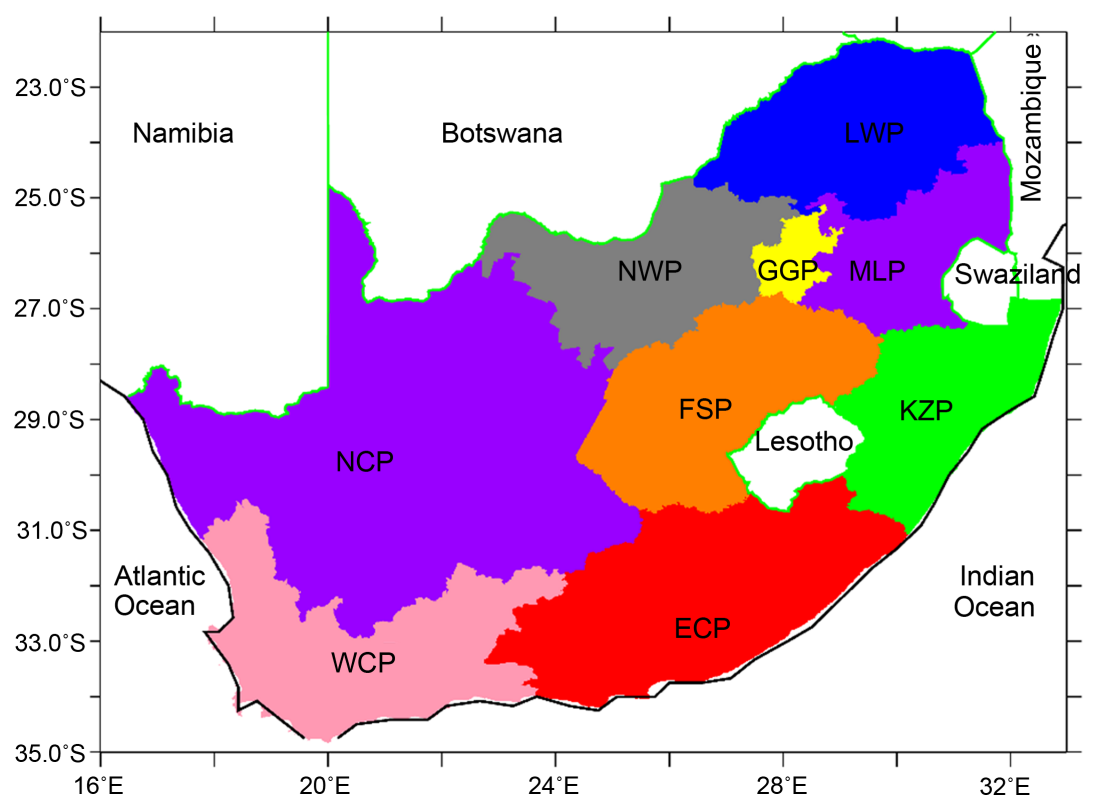

Figure 1. Amended provincial map of the Republic of South Africa. Source: [1]. Interpretations of the provincial abbreviations are presented in Table 1.

Table 1. List of South African provinces and abbreviations used to represent them in this study. Abbreviations of coastal provinces are sufficed with double asterisks $\left({ }^{* *}\right)$. Source: [1].

\begin{tabular}{|c|c|}
\hline Provincial full name & Abbreviation \\
\hline Eastern Cape Province & $\mathrm{ECP}^{* *}$ \\
\hline Free State Province & FSP \\
\hline Gauteng Province & GGP \\
\hline Kwa Zulu Natal Province & $\mathrm{KZP}^{* *}$ \\
\hline Limpopo Province & LMP \\
\hline Mpumalanga Province & MLP \\
\hline Northern Cape Province & $\mathrm{NCP}^{\star *}$ \\
\hline North West Province & NWP \\
\hline Western Cape Province & $\mathrm{WCP}^{\star *}$ \\
\hline
\end{tabular}

temperature, these are hottest and coldest seasons; the rainfall seasons considered are the onset (austral spring), peak (austral summer), and cessation (austral autumn) of the wet season. Rainfall results for the austral winter are largely meaningless except over the Western Cape Province (WCP) which has its rainy season during this period. The next section of this study will briefly discuss the datasets, their sources and the adopted analysis procedures. Sections three and four, respectively, will describe the results and, summary and conclusions.

\section{Datasets and Analysis Procedures}

This study uses the same data described in [1]. These data consist of ensembles from the Hadley Centre Regional Model version 3P (HadRM3P). These simula- 
tions were run under the weather@home/SAF

(https://www.climateprediction.net/weatherathome/) project using the climateprediction.net (CPDN: https://www.climateprediction.net/) facility hosted by the University of Oxford. The project runs the regional atmospheric model HadRM3P over the Southern African domain, nested in the global atmospheric model HadAM3P-N96 [11]. On CPDN framework, simulations are run on volunteers' personal computers around the world. This permits distinctively huge ensemble sizes. Simulations are forced with observed changes in sea ice concentrations, anthropogenic and natural external radiative forcing, and SST. Overall, the experimental setup is very akin to the Atmospheric Model Inter-comparison Project (AMIP: [12] [13] [14]), but dynamically and regionally downscaled to a spatial resolution of $50 \mathrm{~km}$ in order to better resolve topographic niceties that can be very important in mountainous South Africa. Further details on the setup and simulations can be found in [1].

This study uses 100 simulations per month selected according to the same criteria as [1]. HadRM3P ensembles have two distinctive advantages: 1) a huge sample size that allows more clear-cut sampling of the climate distributions and, 2) a relatively high spatial resolution that allows detailed analysis over South African provinces. Here, the simulations are regarded as hindcasts with perfect skill in forecasting the oceanic and radiative forcing states. However, they have no additional skill in forecasting the atmospheric state beyond what is imposed by the oceanic and radiative boundary conditions [1].

This study also adopts the two measures of predictability used by [1] to quantify ensemble spreads. These are the standard deviation (StdDev) and the distance between the 90th and 10th percentiles (RoP) of the simulations. These measures of spreads are computed from the ensembles of monthly near surface air temperature and rainfall from the HadRM3P-50 km model simulations. StdDev utilizes all of the data and it can accurately be calculated from small samples, but it is very sensitive to outliers. Furthermore, while interpretation of observed values within the context of StdDev variations requires the assumption of some distributional form, the RoP does not require such an assumption. RoP, therefore, is considered the opposite of StdDev in all of these three aspects.

Observed anomalies of global gridded monthly SST (Kaplan SST-V2) dataset were acquired from the web portal of the Physical Science Division (PSD) of National Oceanographic and Atmospheric Administration (NOAA/OAR/ESRL) based in Boulder, Colorado, USA-http://www.esrl.noaa.gov/psd. Details on this dataset can be found in [15], [16] and [17].

The correlation coefficient $(\mathbf{r})$ is used to measure co-variation between the de-trended global gridded SST and the de-trended provincial measures of ensemble spread for the relevant seasons and both climate variables. This helps to indicate which areas of the ocean surfaces the South African predictability measures co-vary with, thus helping to concentrate on the selection of the climate indices used in this study. Though $\mathbf{r}$ cannot be used to prove a causal relationship between the two variables, it is however able to evaluate the possibility 
of linear dependence ([18] [19]). All variables are linearly de-trended because this study is interested in the year-to-year variability relevant to seasonal forecasting rather than the long-term trends. However, analyses without the de-trending operations showed negligible differences; in addition, results obtained using Spearman's Ranked Correlation Coefficient showed no difference to those obtained using $\mathbf{r}$, and are therefore not discussed further. All temporal and spatial information are from 1961 to 2009.

\section{Results and Discussion}

\subsection{Co-Variability of Provincial-Seasonal Ensemble Spreads and the Global SST}

Figure 2 and Figure 3 show an illustrative subset of maps indicating correlations between the observed SST and the provincial measures of ensemble spread (the StdDev and the RoP). Specifically, Figure 2 shows the maps of the correlations between the RoP of provincial rainfall and the observed SST during the onset of the rain season (i.e. the austral spring in eight of the provinces and the cessation season for WCP); while Figure 3 displays the maps of the correlations between the provincial temperature StdDev and the observed global SST during the winter season. The trend was removed from all data before calculations because we are interested in the natural variability rather than a possible response

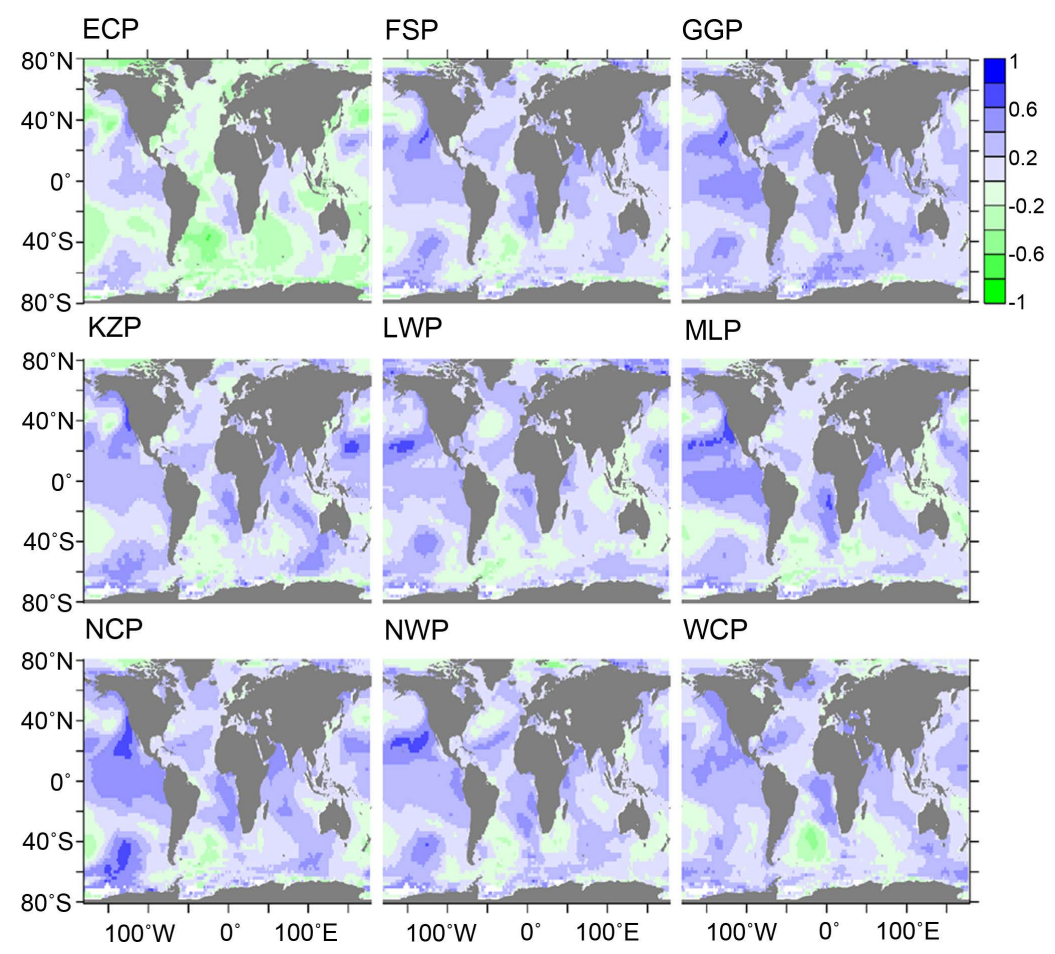

Figure 2. Maps of the correlations between the RoP of the provincial rainfall and the observed global SST anomalies during spring (onset of the rain season for all provinces except WCP, for which it is the cessation period). The trend was removed from all data before calculations while the provincial abbreviations, written at the top left corner of each panel, are as stipulated in Table 1 and Figure 1. 


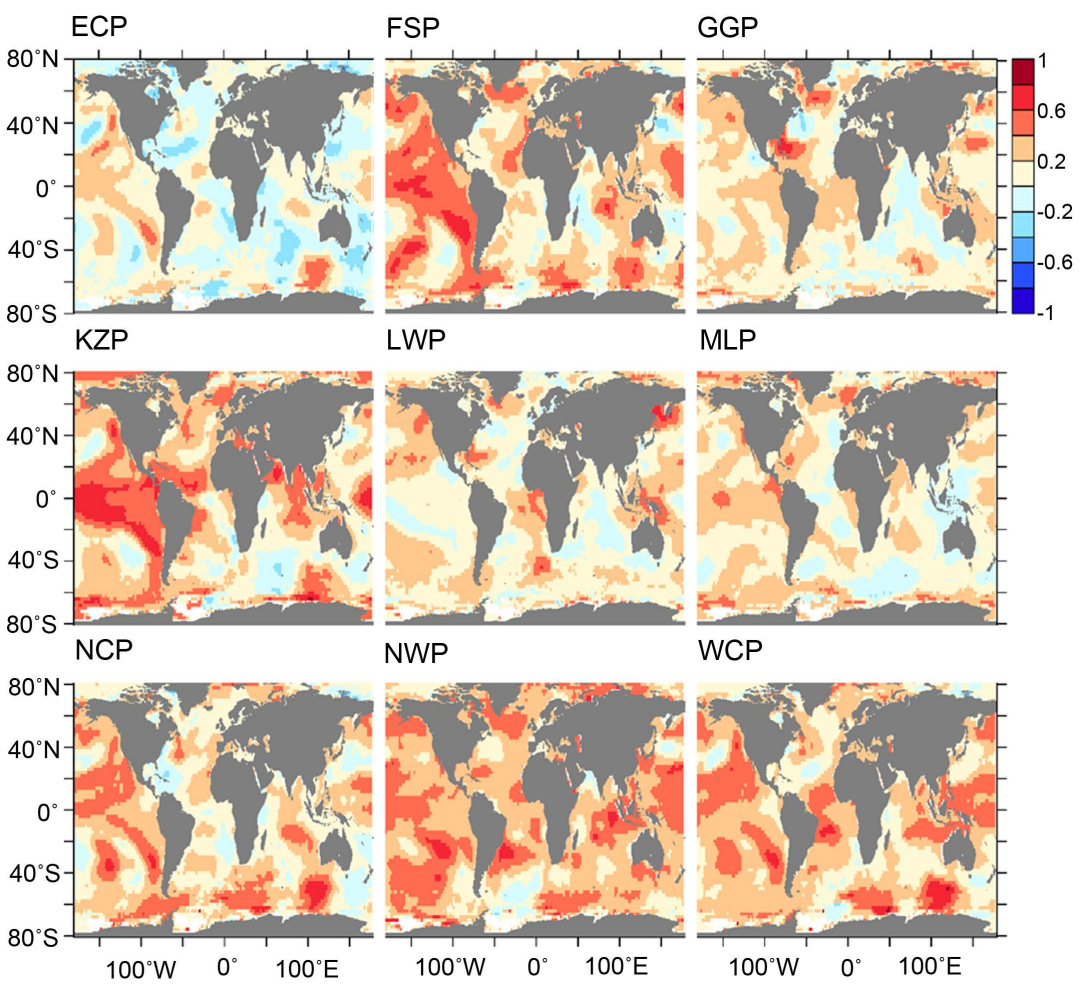

Figure 3. Maps of the correlations between the StdDev of provincial temperature and the observed global SST during the cold winter season. The trend was removed from all data before calculations while the provincial abbreviations, written at the top left corner of each panel, are as stipulated in Table 1 and Figure 1.

to external forcing [1]. Generally, $\mathbf{r}$ ranges from -0.82 to +0.86 for both parameters and measures of spreads for all the seasons (including other seasons that are not shown).

Both provincial measures of ensemble spread, for rainfall and temperature, co-vary noticeably with SSTs over various ocean regions. Most provinces feature considerable positive/negative spread-SST co-variations (i.e. correlations) over the mid latitude to Antarctic/southern zones of the Pacific, Atlantic and Indian Oceans. Many provinces also exhibit some positive/negative co-variations over the tropical axis of these Oceans. The degree of correlation differs substantially from season to season. Co-variation between provincial measures of spread and global SST implies that oceans may provide useful predictors of variations in the predictability of seasonal climate over these provinces.

Some aspects of oceanic variability have been found to be generally useful as predictors for seasonal forecasts; hence they are summarized into climate indices (e.g. [20] [21] [22] [23]). Some of these indices represent variations in ocean temperature signals in the tropical, mid latitudinal and southern parts of Pacific, Atlantic and Indian Oceans where we have noted considerable correlations with the ensemble spread. Thus, there is the possibility that along with being useful predictors of seasonal climate over South Africa, these indices may also be useful predictors of the potential skill of that forecast. 
In view of the findings above, the climate indices to be considered in this study are the Antarctic Oscillation (AAO), Indian Ocean Dipole (IOD), Multivariate ENSO Index (MEI) and Tropical Southern Atlantic (TSA). Others are the Benguela Niño (BGN), South Indian Ocean Index (SIO) and Southwest Indian Ocean Index (SWI). These indices have been shown to be relevant to large-scale seasonal circulation over the South African region. On Table 2 are brief descriptions of the climate indices considered in this study and the source of the time series used in this study. The correlations of the de-trended provincial-seasonal measures of spread with the de-trended climatic indices are calculated on inter-annual time scales on seasonal bases. Since the data used in this study have large sample sizes for each year, a Monte-Carlo bootstrap re-sampling procedure ([24] [25] [26]) is used to sample uncertainty in the results, with the re-sampling conducted 1000 times.

\subsection{Co-Variability of Provincial-Seasonal Ensemble Spreads and the Climate Indices}

\subsubsection{Rainfall}

Panels in Figure 4, which depict the seasonal correlations between measures of spread (RoP and StdDev) for rainfall and climate indices, show that correlations (r) range from considerably weak to moderate in both directions of direct and inverse relationships. For instance, average $\mathbf{r}$ spans between $+/-0.47$; and when the error bars are considered, the spread is $+/-0.8$.

The error bars in Figure 4 show that there are obvious cases of non-zero $r$ which are consistent across the two measures of spread. This means that climate

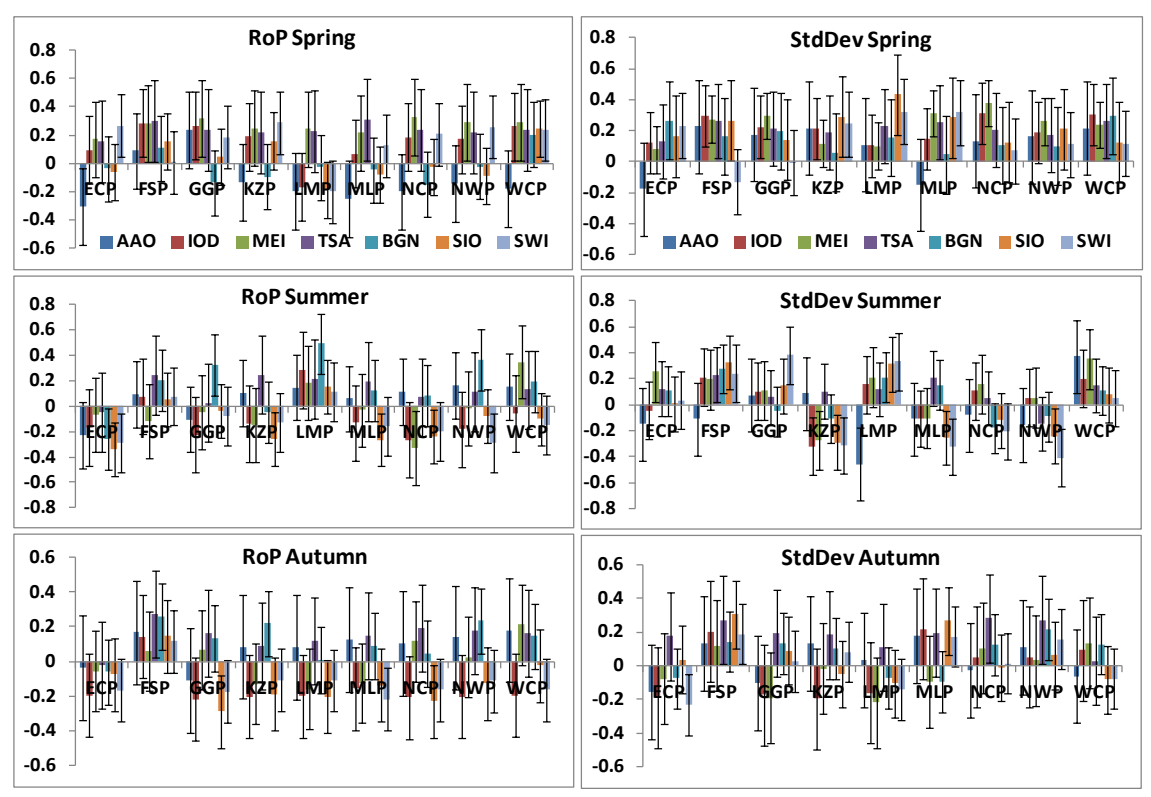

Figure 4. Seasonal correlations between measures of spread for rainfall (for the nine South African Provinces) and climate indices. RoP is the 10 - 90th percentile range and StdDev the standard deviation. Error bars indicate $90 \%$ confidence intervals estimated through a Monte-Carlo bootstrap procedure. Provincial and climate indices abbreviations are as tabularized on Table 1 and Table 2 respectively. 
Table 2. List and brief description of climate indices used in this study.

\begin{tabular}{|c|c|c|c|}
\hline Climate index & Abbreviation & Description & Reference \\
\hline $\begin{array}{l}\text { Antarctic } \\
\text { Oscillation }\end{array}$ & $\mathrm{AAO}$ & $\begin{array}{l}\text { Normalized difference in the zonal mean sea-level pressure pattern between } 60^{\circ} \mathrm{S} \\
\text { and } 40^{\circ} \mathrm{S} \text {. It is a measure of equator-ward/pole-ward shifts in the southern mid } \\
\text { latitude storm track; therefore, a measure of atmospheric circulation rather than SSTs, } \\
\text { but we include it here because it is such a dominant descriptor of southern } \\
\text { mid-latitude circulation. Source: } \\
\text { https://www.esrl.noaa.gov/psd/data/20thC_Rean/timeseries/monthly/AAO/. }\end{array}$ & [28] [29] [30] \\
\hline $\begin{array}{c}\text { Indian } \\
\text { Ocean Dipole }\end{array}$ & IOD & $\begin{array}{l}\text { A shift of SST between positive, neutral and negative phases over the western and } \\
\text { eastern Indian Ocean. Constructed from SST variability over the Indian Ocean for } \\
35^{\circ} \mathrm{E}-115^{\circ} \mathrm{E} \text { and } 25^{\circ} \mathrm{S}-20^{\circ} \mathrm{N} \text { domain using the methodology of [34]. It describes } \\
\text { the center of the Walker circulation ascending branches over the eastern } \\
\text { Indian Ocean and the south eastern corner of the South Atlantic Ocean. }\end{array}$ & [31] [32] [33] \\
\hline $\begin{array}{l}\text { Multivariate } \\
\text { ENSO Index }\end{array}$ & MEI & $\begin{array}{l}\text { Measure of combined atmosphere-ocean phenomena, representing shifts of warm } \\
\text { surface waters and associated atmospheric convection back and forth across the } \\
\text { tropical Pacific Ocean. Synonymous with El Nino-Southern Oscillation (ENSO) } \\
\text { phenomena. ENSO has influence on South African rainfall anomalies which may occur } \\
\text { through modulation of the local Walker circulation and SSTs in the neighboring Indian } \\
\text { and Atlantic Oceans. Source: } \mathrm{http://www.esrl.noaa.gov/psd/data/correlation/mei.data.}\end{array}$ & $\begin{array}{c}{[20][21][22]} \\
{[23][35][36][37]}\end{array}$ \\
\hline $\begin{array}{c}\text { Tropical } \\
\text { Southern Atlantic }\end{array}$ & TSA & $\begin{array}{l}\text { A measure of SST gradient over the southern parts of equatorial Atlantic Ocean. } \\
\text { Several idealized climate model experiments shows that TSA exhibits a } \\
\text { self-evident boost in daily rainfall and rainfall extremes over southern Africa, } \\
\text { via locally-based effects such as increased convection and remotely-based } \\
\text { effects such as an adjustment of the Walker-type circulation. Source: } \\
\text { http://www.esrl.noaa.gov/psd/data/correlation/tsa.data. }\end{array}$ & [38] [39] \\
\hline $\begin{array}{l}\text { Benguela } \\
\text { Nino }\end{array}$ & BGN & $\begin{array}{l}\text { BGN dataset is similar to those of TSA described by [38]. It is a measure of SST } \\
\text { anomaly gradient over the south-eastern Equatorial Atlantic. The influence of the } \\
\text { tropical south-eastern Atlantic SST anomalies on the western Southern African rainfall } \\
\text { and temperature may be enhanced if the easterly inflow of moisture from the western } \\
\text { Indian Ocean is greater than average. Therefore, local evaporation, coupled with } \\
\text { enhanced instability, over the south-eastern Atlantic Ocean act to supplement the } \\
\text { precipitation derived from the Indian Ocean source rather than providing a dominant } \\
\text { source of moisture. Its construction is however restricted to SST anomalies over the } \\
\text { South Atlantic Ocean rectangular domain } 15^{\circ} \mathrm{E}-0^{\circ} \mathrm{E} \text { and } 30^{\circ} \mathrm{S}-5^{\circ} \mathrm{S} \text { in this study. }\end{array}$ & $\begin{array}{c}{[38][39]} \\
{[40][41][42]}\end{array}$ \\
\hline $\begin{array}{l}\text { South Indian } \\
\text { Ocean Index }\end{array}$ & SIO & $\begin{array}{l}\text { SIO dataset, described by [43], is akin to IOD dataset. The exception is that SIO is } \\
\text { strictly constructed from SST variability over the Southern Indian Ocean } \\
\text { rectangular domain } 50^{\circ} \mathrm{E}-115^{\circ} \mathrm{E} \text { and } 35^{\circ} \mathrm{S}-0^{\circ} \mathrm{S} \text {, also, using the methodology of [34]. }\end{array}$ & [31] [43] \\
\hline $\begin{array}{l}\text { Southwest Indian } \\
\text { Ocean Index }\end{array}$ & SWI & $\begin{array}{l}\text { SWI dataset is very similar to SIO except that SWI is constructed from SST variability } \\
\text { over the Southwestern Indian Ocean rectangular domain } 35^{\circ} \mathrm{E}-70^{\circ} \mathrm{E} \text { and } 40^{\circ} \mathrm{S}-20^{\circ} \mathrm{S} \text {. } \\
\text { Warm and cold conditions over the Southwest Indian Ocean have been linked, } \\
\text { respectively, with wet and dry conditions over South Africa and vice versa. This is } \\
\text { regardless of the atmospheric and oceanic mechanisms by which they arise. }\end{array}$ & [41] [44] \\
\hline
\end{tabular}

indices co-vary significantly with measures of spread on seasonal time scales over a number of provinces and seasons. During the rainfall onset period i.e. spring season, the figure shows that measures of spread over many provinces co-vary with more than one climate index. For instance, they co-vary considerably with IOD over Free State Province and GGP; with MEI over FSP, GGP, NCP, North West Province and WCP; with TSA over FSP and GGP; and, with SWI over the Eastern Cape Province and KwaZulu Natal Province. During the rain peak period in summer, both measures of spread co-vary with MEI over WCP 
and with SIO over KZP and Mpumalanga Province (MLP). They also co-vary with SWI over NWP (Figure 4). During the rainfall cessation period i.e. autumn (Figure 4), measures of spread co-vary with TSA over FSP and with BGN over NWP. These co-variabilities suggest that the climate factors controlling the degree to which the seasonal rainfall may be precisely quantitatively forecast over the South African provinces may both be locally and remotely based. Results also suggest that all significant predictors of are of tropical origin.

However, instances of major disagreements between RoP and StdDev, regarding the co-variability between climate indices and measures of spread, are noticed in AAO over LMP and Eastern Cape Province during rainfall peak and onset seasons respectively (Figure 4). In the same manner, there are disagreements between measures of spread in BGN over FSP during autumn. In general, the degrees of co-variation, between climate indices and measures of spread, differ from index-to-index, season-to-season and province-to-province. There is no gross spatial pattern to the co-variations at the national scale.

There is evidence of physically-based co-variation between climate indices and measures of spread. For instance, the frequencies (i.e. enumeration) of province-season non-zero correlations, at the $10 \%$ significant level, have more than the required statistical provincial-seasonal realizations (Table 3). For each variable, season, and province in Table 3, if the indices and the measures of spread are independent then approximately 1 out of 9 provinces per index would be expected to be significant (i.e. non-zero $\mathbf{r}$ ) by random chance. Frequencies of non-zero $\mathbf{r}$ that are above 1 are thus suggestive that we are finding evidence of physically-based co-variation. However, the 1-in-9-expected-by-chance rule of thumb should be considered a bare minimum, rather than sufficient, because the provinces are hardly independent of each other climatologically. It is challenging to estimate the degree to which actual inter-region and inter-season correlation modifies the required minimum (and hence field significance) without resorting to much larger ensembles. Instead, we can identify the minimum effective degrees of freedom required for specific counts to remain locally significant. For instance, supposing eight effective degrees of freedom from four independent seasons and the nine provinces behaving as two independent units, a count of at least 12/36 would be required for each climate index and spread measure (combining the counts of all of the seasons). This is satisfied for StdDev with the MEI, SIO, and SWI indices. Adding two additional spatial degrees of freedom would mean that StdDev with BGN and RoP with BGN, SIO, and SWI would also pass. Therefore, these calculations indicate that MEI, BGN, SIO and SWI have a significant influence on rainfall predictability over South Africa throughout the year. It should be noted though that TSA and, particularly, IOD are also highly locally significant during the onset period (Table 3). Their influence on rainfall predictability, however, tends to be weakest during rainfall peak and cessation periods.

Though not included in Figure 4, it is nevertheless worthy to note that both measures of spread co-vary significantly with MEI during the dry winter season 
Table 3. Frequency of non-zero correlations between provincial-seasonal measures of spread and large-scale climate indices. At random, only 1 out of 9 provinces per index are expected to have correlations considerably different from zero at the two-sided $10 \%$ significant level. On rainfall column, note that the peak and dry seasons are respectively dry and wet seasons for WCP.

\begin{tabular}{|c|c|c|c|c|c|c|}
\hline \multirow{2}{*}{ Climate index } & \multicolumn{3}{|c|}{ Rainfall } & \multicolumn{3}{|c|}{ Temperature } \\
\hline & Season & RoP & StdDev & Season & RoP & StdDev \\
\hline $\mathrm{AAO}$ & Onset & 1 & 0 & & & \\
\hline IOD & (Spring) & 3 & 5 & & & \\
\hline MEI & & 4 & 6 & & & \\
\hline TSA & & 2 & 3 & & & \\
\hline BGN & & 0 & 2 & & & \\
\hline SIO & & 1 & 3 & & & \\
\hline SWI & & 4 & 4 & & & \\
\hline AAO & & 0 & 2 & & 0 & 0 \\
\hline IOD & Peak & 0 & 1 & Hot & 1 & 2 \\
\hline MEI & (Summer) & 2 & 3 & (Summer) & 3 & 7 \\
\hline TSA & & 0 & 1 & & 4 & 4 \\
\hline BGN & & 2 & 2 & & 4 & 2 \\
\hline SIO & & 4 & 5 & & 0 & 1 \\
\hline SWI & & 2 & 6 & & 3 & 7 \\
\hline $\mathrm{AAO}$ & & 0 & 0 & & & \\
\hline IOD & Cessation & 0 & 0 & & & \\
\hline MEI & (Autumn) & 0 & 0 & & & \\
\hline TSA & & 1 & 3 & & & \\
\hline BGN & & 3 & 1 & & & \\
\hline SIO & & 2 & 2 & & & \\
\hline SWI & & 1 & 2 & & & \\
\hline $\mathrm{AAO}$ & & & & & 0 & 0 \\
\hline IOD & & & & Cold & 1 & 3 \\
\hline MEI & & & & (Winter) & 2 & 6 \\
\hline TSA & & & & & 0 & 1 \\
\hline BGN & & & & & 2 & 2 \\
\hline SIO & & & & & 5 & 4 \\
\hline SWI & & & & & 3 & 4 \\
\hline
\end{tabular}

over the Northern Cape Province (NCP) and WCP. Measures of spread over Eastern Cape Province and Gauteng Province (GGP) also co-vary considerably with AAO and TSA, respectively, during this season. In addition, measures of spread over Limpopo Province (LMP) co-vary considerably with BGN, also 
during the winter season. However, provincial rainfall totals in this season are so small as to have any impacts, except over the Eastern Cape Province and WCP. Meanwhile, studies have shown that rainfall over Western and Eastern Cape Provinces in winter and year-round respectively result from frontal systems which are modulated by southern mid-latitude circulation [27]; and that the AAO provides an effective measure of the equator-ward/pole-ward variations in the position of the southern mid latitude circulation [28]. Thus, the general lack of significant co-variation between the measures of spread and AAO over Western and Eastern Cape Provinces (not shown) suggests that the predictability of seasonal rainfall as a result of variations in the frequency and intensity of mid-latitude flow structures, such as cut-off-lows, is not related to the variations in the frequency and intensity themselves, at least in a linear way.

\subsubsection{Temperature}

For near surface temperature, correlations span -0.6 to +0.8 and there is no particular pattern in the correlations between measures of spread and climate indices during the two seasons considered (i.e. summer and winter; Figure 5). For example, both RoP and StdDev agree that there are considerable co-variations, in summer, with MEI over KwaZulu Natal, Western and Eastern Cape Provinces, with IOD over the Eastern Cape Province; with TSA over FSP, MLP and NWP; with BGN over GGP and NWP; with SWI over FSP, GGP and NWP. In winter, measures of spread agreeably co-vary with MEI over KZP and WCP; with BGN over LMP; with SIO over FSP and KZP; and, with SWI over the Eastern Cape Province, KZP and MLP (Figure 5). These imply that all significant predictors of seasonal temperature over South African provinces are of tropical origin and that the climate factors controlling the extent to which seasonal temperatures may be precisely forecast over the same domain may both be locally and remotely based.

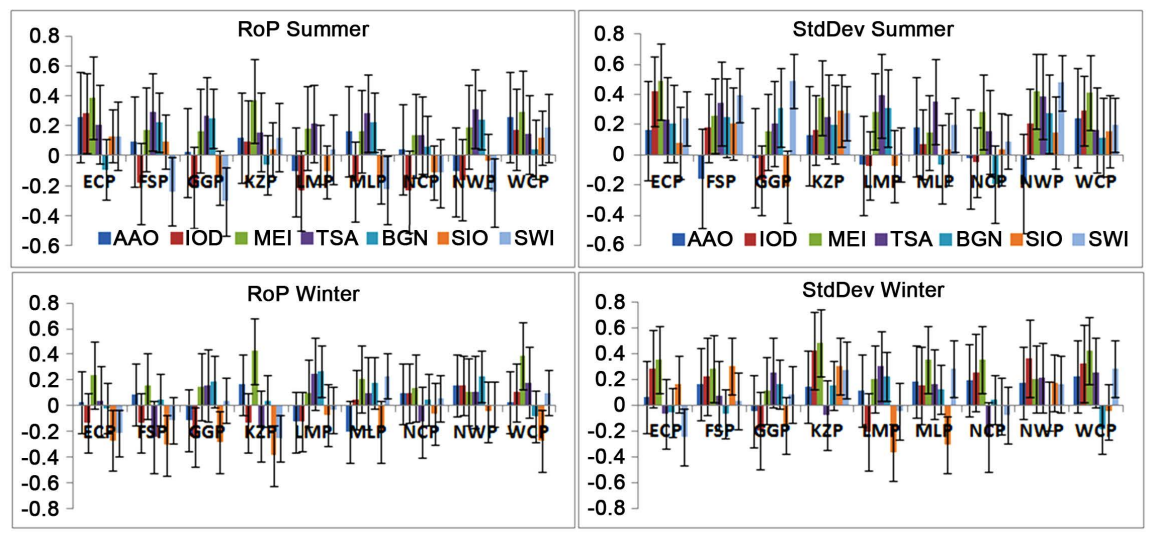

Figure 5. Correlations between measures of spread for temperature (for the nine South African Provinces during summer and winter seasons) and climate indices. RoP is the 10 - 90th percentile range and StdDev the standard deviation. Error bars indicate 90\% confidence intervals estimated through a Monte-Carlo bootstrap procedure. Provincial and climate indices abbreviations are as tabularized on Table 1 and Table 2 respectively. 
For near surface temperature, some of the frequencies of province-season non-zero $\mathbf{r}$ also have more than the required statistical provincial-seasonal realizations (Table 3). However, at least in part because of the smaller sample size (only two seasons) than used for precipitation, it is less clear that these indicate true relationships. For instance, supposing four effective degrees of freedom from two independent seasons and the nine provinces behaving as two independent units, a count of at least 9/18 would be required for each climate index and spread measure (combining the counts of both the hot and cold seasons). This is only satisfied for StdDev with the MEI and SWI.

\section{Summary and Conclusions}

In order to address to the probing question of whether there are any SST influences on the range of possible seasonal climates, this study further examined the co-variability between indices of large-scale climate variability and the variations in the ensemble spread of simulations of an atmospheric regional climate model over South Africa. Within the HadAM3P-N96/HadRM3P-50 km regional modeling framework used in this study, it has been established that the measures of the range of predictability, vis-à-vis measures of spread, over South African provinces significantly co-vary with the observed global SST far and near on seasonal time scales, suggesting that the climatic driving factors/forces may be locally or remotely based. Analyses revealed that the degrees of co-variability differ from index-to-index, season-to-season and province-to-province over South Africa. Nevertheless, this study affirms that ENSO (as described by MEI), IOD, BGN and SWI are the most influential in altering the spread of seasonal rainfall and temperature over South Africa in these simulations.

These findings are consistent with the connections between large-scale SST and remote atmospheric anomalies and South African climate noted by [22] [23] [31]-[44]. [22] and [23] found that ENSO has the largest influence on South African rainfall, vis-à-vis temperature, anomalies. Our results are also consistent with findings of [31] [41] [43] and [44] that IOD and SWI also influence and modulate South(ern) African rainfall, vis-à-vis temperature, anomalies. They concluded that positive and negative SST anomalies, respectively, over the west and East Indian Ocean increase rainfall occurrences over southeastern Africa. They then adduced that enhanced evaporation occurs over the warm parts of the southwest Indian Ocean and that this moist air is transported towards southeastern Africa by a low-pressure anomaly that is generated over the warm parts. This enhances the onshore flow. In the same manner, [39] [41] and [42] found that variations in SST anomalies over the tropical southeastern parts of Atlantic Ocean also appear to have some role in influencing climate predictability all seasons, and most especially in summer season. This study has built on the earlier work by revealing that the effectiveness of these predictors may be modulated by other aspects of year-to-year variability.

These results of this study suggest that there may be limits to the extent to which inter-annual variations in the predictability of seasonal climate might be 
understood, either because: 1) all significant climate predictors are of tropical origin, 2) the co-variability of measures of predictability with climate predictors are, on the average, weak, 3) climate predictors are more complex in nature than can be represented by the traditionally simple climate indices, or 4) because the co-variability of measures of predictability with climate predictors are non-linear in nature.

The results presented here come from analysis of a single climate modeling system; therefore, the robustness of the results to model selection is unknown. Moreover, this modeling system is not particularly modern and certainly does not represent a state-of-the-art model. But this study could not be conducted with a computationally expensive state-of-the-art model, because no computational resources exist, at the moment, for running the large ensembles of high-spatial-resolution simulations required to precisely characterize variations in ensemble spread at the sub-national level; therefore, this data set is currently unique. Whether another model would reveal the same relationship is unknown, consequently the specific values should not be taken too literally, but rather as indicative of the plausibility that regional predictability can itself be modulated from year to year.

Another concern is that this study only looked for linear relationships between climate predictors and measures of predictability. Although significant correlations were found, there was no indication of the mechanism for causation. It may be that climate indices are influencing the atmosphere in a way that affects predictability of seasonal climate, or that climate indices are responding to some other driver which is also affecting the seasonal climate predictability over South Africa. Such a driver could be elsewhere within the climate system or could be external in nature, for instance through anthropogenic emissions [1]. Despite the removal of linear trends from the time series of the analysis, nonlinear responses to external drivers (e.g. aerosol concentrations) may still be present in the data, as suggested by the mostly positive correlations for temperature predictability against SSTs globally. Beyond all these, the mechanisms through which various predictors could affect the spread of seasonal climate simulations over South Africa remain undefined.

\section{Acknowledgements}

The authors would like to thank all volunteers who spared their time to run the weather at home/SAF model simulations, from which data used in this study is based, on their personal computers. We also like to acknowledge invaluable advice from Bruce Hewitson, Tolu Aina, and Chris Rye; technical assistance from Phillip Mukwena; technical assistance on the weather at home/SAF project from Chris Forest and Chuck Pavolski at Pennsylvania State University, and the PRECIS team at the UK Met Office. KAL was funded by grants from the South African Water Research Commission (WRC-Project K5/2067/1). DAS was supported by the Regional and Global Climate Modeling Program and the Earth System Modeling Program Office of Biological and Environmental Research in the Department 
of Energy Office of Science under contract number DE-AC02-05CH11231. The weather at home/SAF project was developed with support from Microsoft Research.

\section{Conflicts of Interest}

The authors declare that they have no competing interests regarding the publication of this paper.

\section{References}

[1] Lawal, K.A., Stone, D.A., Aina, T., Rye, C. and Abiodun, B.J. (2015) Trends in the Potential Spread of Seasonal Climate Simulations over South Africa. International Journal of Climatology, 35, 2193-2209. https://doi.org/10.1002/joc.4234

[2] Landman, W.A., Botes, S., Goddard, L. and Shongwe, M. (2005) Assessing the Predictability of Extreme Rainfall over Southern Africa. Geophysical Research Letters, 32, L23818. https://doi.org/10.1029/2005GL023965

[3] Landman, W.A. and Goddard, L. (2005) Predicting Southern African Summer Rainfall Using a Combination of MOS and Perfect Prognosis. Geophysical Research Letters, 32, L15809. https://doi.org/10.1029/2005GL022910

[4] Friederichs, P. and Paeth, H. (2006) Seasonal Prediction of African Rainfall with ECHAM4-T42 Ensemble Simulations Using a Multivariate MOS Re-Calibration Scheme. Climate Dynamics, 27, 761-786.

https://doi.org/10.1007/s00382-006-0154-4

[5] Murphy, J.M. (1988) The Impact of Ensemble Forecasts on Predictability. Quarterly Journal of the Royal Meteorological Society, 114, 463-493.

https://doi.org/10.1002/qj.49711448010

[6] Whitaker, J.S. and Loughe, A.F. (1998) The Relationship between Ensemble Spread and Ensemble Mean Skill. Monthly Weather Review, 126, 3292-3302. https://doi.org/10.1175/1520-0493(1998)126<3292:TRBESA >2.0.CO;2

[7] Tang, Y., Lin, H. and Moore, A.M. (2008) Measuring the Potential Predictability of Ensemble Climate Predictions. Journal of Geophysical Research, 113, D04108. https://doi.org/10.1029/2007JD008804

[8] Nester, T., Komma, J., Viglione, A. and Bloschl, G. (2012) Flood Forecast Errors and Ensemble Spread-A Case Study. Water Resource Research, 48, W10502. https://doi.org/10.1029/2011WR011649

[9] Johnston, P.A., Archer, E.R.M., Vogel, C.H., Bezuidenhout, C.N., Tennant, W.J. and Kuschke, R. (2004) Review of Seasonal Forecasting in South Africa: Producer to End-User. Climate Research, 28, 67-82. https://doi.org/10.3354/cr028067

[10] Kruger, A.C. (2006) Observed Trends in Daily Precipitation Indices in South Africa: 1910-2004. International Journal of Climatology, 26, 2275-2285. https://doi.org/10.1002/joc.1368

[11] Jones, R.G., Noguer, M., Hassell, D.C., Hudson, D., Willson, S.S., Genkins, G.J. and Mitchell, J.F.B. (2004) Generating High Resolution Climate Change Scenarios Using PRECIS. Technical Report, Met Office Hadley Centre, Exeter, 40 p.

[12] Gates, W.L. (1992) AMIP: The Atmospheric Model Intercomparison Project. Bulletin of the American Meteorological Society, 73, 1962-1970. https://doi.org/10.1175/1520-0477(1992)073<1962:ATAMIP>2.0.CO;2

[13] Zwiers, F.W. (1996) Interannual Variability and Predictability in an Ensemble of 
AMIP Climate Simulations Conducted with the CCC GCM2. Climate Dynamics, 12, 825-847. https://doi.org/10.1007/s003820050146

[14] Frei, A. and Robinson, D.A. (1998) Evaluation of Snow Extent and Its Variability in the Atmospheric Model Intercomparison Project. Journal of Geophysical Research, 13, 8859-8871. https://doi.org/10.1029/98JD00109

[15] Parker, D.E., Jones, P.D., Folland, C.K. and Bevan, A. (1994) Inter-Decadal Changes of Surface Temperature since the Late Nineteenth Century. Journal of Geophysical Research, 99, 373-399. https://doi.org/10.1029/94JD00548

[16] Reynolds, R.W. and Smith, T.M. (1994) Improved Global Sea Surface Temperature Analysis Using Optimum Interpolation. Journal of Climate, 7, 929-948. https://doi.org/10.1175/1520-0442(1994)007<0929:IGSSTA>2.0.CO;2

[17] Kaplan, A., Cane, M., Kushnir, Y., Clement, A., Blumenthal, M. and Rajagopalan, B. (1998) Analyses of Global Sea Surface Temperature 1856-1991. Journal of Geophysical Research, 103, 567-1589. https://doi.org/10.1029/97JC01736

[18] Montgomery, D.C. (1991) Introduction to Statistical Quality Control. John Wiley, New York, 674 p.

[19] Montgomery, D.C. and Peck, E.A. (1982) Introduction to Linear Regression Analysis. John Wiley, New York, 504 p.

[20] Reason, C.J.C., Allan, R.J., Lindesay, J.A. and Ansell, T.J. (2000) ENSO and Climatic Signals across the Indian Ocean Basin in the Global Context: Part I, Inter-Annual Composite Patterns. International Journal of Climatology, 20, 1285-1327. https://doi.org/10.1002/1097-0088(200009)20:11<1285::AID-JOC536>3.0.CO;2-R

[21] Reason, C.J.C. and Jagadheesha, D. (2005) A Model Investigation of Recent ENSO Impacts over Southern Africa. Meteorology and Atmospheric Physics, 89, 181-205. https://doi.org/10.1007/s00703-005-0128-9

[22] Fauchereau, N., Pohl, B., Reason, C.J.C., Rouault, M. and Richard, Y. (2009) Recurrent Daily OLR Patterns in the Southern Africa/Southwest Indian Ocean Region, Implications for South African Rainfall and Teleconnections. Climate Dynamics, 32, 575-591. https://doi.org/10.1007/s00382-008-0426-2

[23] Landman, W.A. and Beraki, A. (2010) Multi-Model Forecast Skill for Mid-Summer Rainfall over Southern Africa. International Journal of Climatology, 32, 303-314. https://doi.org/10.1002/joc.2273

[24] Stephenson, D.B. and Doblas-Reyes, F.J. (2000) Statistical Methods for Interpreting Monte-Carlo Ensemble Forecasts. Tellus, 52A, 300-322. https://doi.org/10.3402/tellusa.v52i3.12267

[25] Johnson, R.W. (2001) An Introduction to the Bootstrap. Teaching Statistics, 23, 49-54. https://doi.org/10.1111/1467-9639.00050

[26] Buhlmann, P. (2002) Bootstraps for Time Series. Statistical Science, 17, 52-72. https://doi.org/10.1214/ss/1023798998

[27] Tyson, P.D. and Preston-Whyte, R.A. (2000) The Weather and Climate of Southern Africa. Second Edition, Oxford University Press, Cape Town, 228-236 and 364-376.

[28] Thompson, D.W.J. and Wallace, J.M. (2000) Annular Modes in the Extra-Tropical Circulation. Part I: Month-to-Month Variability. Journal of Climate, 13, 1000-1016. https://doi.org/10.1175/1520-0442(2000)013<1000:AMITEC>2.0.CO;2

[29] Kalnay, E., et al. (1996) The NCEP/NCAR 40-Year Reanalysis Project. Bulletin of the American Meteorological Society, 77, 437-471. https://doi.org/10.1175/1520-0477(1996)077<0437:TNYRP>2.0.CO;2

[30] Rayner, N.A., Parker, D.E., Horton, E.B., Folland, C.K., Alexander, L.V., Rowell, 
D.P., Kent, E.C. and Kaplan, A. (2003) Global Analyses of Sea Surface Temperature, Sea Ice, and High Marine Air Temperature since Late Nineteenth Century. Journal of Geophysical Research, 108, 4407. https://doi.org/10.1029/2002JD002670

[31] Reason, C.J.C. (2001) Subtropical Indian Ocean SST Dipole Events and Southern African Rainfall. Geophysical Research Letters, 28, 2225-2227. https://doi.org/10.1029/2000GL012735

[32] Annamalai, H., Xie, S.-P., McCreary, J.-P. and Murtugudde, R. (2005) Impacts of Indian Ocean Sea Surface Temperature on Developing El Nino. International Journal of Climatology, 18, 302-319. https://doi.org/10.1175/JCLI-3268.1

[33] Izumo, T., Vialard, J., Lengaigne, M., de Boyer Montegut, C., Behera, S.K., Luo, J.-J., Cravatte, S., Masson, S. and Yamagata, T. (2010) Influence of the State of the Indian Ocean Dipole on the Following Year's El Nino. Nature Geoscience, 3, 168-172. https://doi.org/10.1038/ngeo760

[34] Behera, S.K. and Yamagata, T. (2001) Subtropical SST Dipole Events in the Southern Indian Ocean. Geophysical Research Letters, 28, 327-330. https://doi.org/10.1029/2000GL011451

[35] Rasmusson, E.G. and Carpenter, T.H. (1982) Variations in the Tropical Sea Surface Temperature and Surface Wind Fields Associated with the Southern Oscillation/El Nino. Monthly Weather Review, 110, 354-384. https://doi.org/10.1175/1520-0493(1982)110<0354:VITSST>2.0.CO;2

[36] Camberlin, P., Janicot, S. and Poccard, I. (2001) Seasonality and Atmospheric Dynamics of the Teleconnection between African Rainfall and Tropical Sea-Surface Temperature: Atlantic vs. ENSO. International Journal of Climatology, 21, 973-1005. https://doi.org/10.1002/joc.673

[37] Wolter, K. and Timlin, M.S. (2011) El Nino Southern Oscillation Behavior since 1871 as Diagnosed in an Extended Multivariate ENSO Index. International Journal of Climatology, 31, 1074-1087. https://doi.org/10.1002/joc.2336

[38] Enfield, D.B., Mestas-Nunez, A.M., Mayer, D.A. and Cid-Serrano, L. (1999) How Ubiquitous Is the Dipole Relationship in Tropical Atlantic Sea Surface Temperatures? Journal of Geophysical Research, 104, 7841-7848. https://doi.org/10.1029/1998JC900109

[39] Williams, C.J.R., Kniveton, D.R. and Layberry, R. (2008) Influence of South Atlantic Sea Surface Temperatures on Rainfall Variability and Extremes over Southern Africa. Journal of Climate, 21, 6498-6520. https://doi.org/10.1175/2008JCLI2234.1

[40] Walker, N.D. (1990) Links between South African Summer Rainfall and Temperature Variability of the Agulhas and Benguela Current Systems. Journal of Geophysical Research, 95, 3297-3319. https://doi.org/10.1029/JC095iC03p03297

[41] Reason, C.J.C. (1998) Warm and Cold Events in the Southeast Atlantic/Southwest Indian Ocean Region and Potential Impacts on Circulation and Rainfall over Southern Africa. Meteorology and Atmospheric Physics, 69, 49-65. https://doi.org/10.1007/BF01025183

[42] Rouault, M., Florenchie, P., Fauchereau, N. and Reason, C.J.C. (2003) South East Tropical Atlantic Warm Events and Southern African Rainfall. Geophysical Research Letters, 30, 8009. https://doi.org/10.1029/2002GL014840

[43] Reason, C.J.C. (2002) Sensitivity of the Southern African Circulation to Dipole Sea-Surface Temperature Patterns in the South Indian Ocean. International Journal of Climatology, 22, 377-393. https://doi.org/10.1002/joc.744

[44] Reason, C.J.C. and Mulenga, H.M. (1999) Relationships between South African 
Rainfall and SST Anomalies in the South West Indian Ocean. International Journal Climatology, 19, 1651-1673.

https://doi.org/10.1002/(SICI)1097-0088(199912)19:15<1651::AID-JOC439>3.0.CO; 2-U 